\title{
COMPARATIVE EVALUATION OF A MIXTURE OF ATRACURIUM AND TRAMADOL OR KETOROLAC AS AN ADJUNCT TO LOW DOSE LIGNOCAINE IN INTRAVENOUS REGIONAL ANESTHESIA
}

Sunana Gupta, Bharat Bhushan Kapoor, Nandita Mehta, Satya Dev Gupta, Sidharth Verma

1. Assistant Professor, Department of Anesthesiology, ASCOMS \& H, Jammu.

2. Professor \& HOD, Department of Anesthesiology, GMC, Jammu.

3. Professor \& HOD, Department of Anesthesiology, ASCOMS \& H, Jammu.

4. Ex - Profesoor \& HOD, Department of Anesthesiology GMC, Jammu.

5. PG Student, Department of Anesthesiology, ASCOMS \& H, Jammu.

\section{CORRESPONDING AUTHOR}

Dr. Sunana Gupta,

H. No. 14, Indira Colony,

Camp Road, Talab Tillo,

Jammu - 180002.

E-mail: sunaynaarnav@yahoo.com

Ph: 00919419160705

ABSTRACT: BACKGROUND: Purpose of the study was to evaluate the efficacy of Atracurium as adjuvant with tramadol or Ketorolac in reducing the dose of lignocaine used for intravenous regional anesthesia thereby decreasing the chances of systemic toxicity of lignocaine. PATIENTS AND METHODS: Sixty adult patients of ASA grade I and II were divided into three equal groups of twenty each in randomized double blind manner. Group I patients received $40 \mathrm{ml}$ of $0.5 \%$ lignocaine. Group II and III received $40 \mathrm{ml}$ of $0.25 \%$ lignocaine with addition of 2 mg Atracurium and $50 \mathrm{mg}$ tramadol while in Group III, tramadol was replaced with $30 \mathrm{mg}$ of Ketorolac. Onset of sensory and motor block, intraoperative degree of analgesia, intraoperative and postoperative complications were recorded in all the three groups. RESULTS: There was no significant difference between the groups with respect to age, weight and sex distribution. Mean time of onset of motor block in group I, II and III was 4.15+0.81, 11.7+0.86 and 14.2+0.69 minutes respectively which was statistically significant $(\mathrm{p}<0.001)$. Mean time of onset of sensory block in groups I, II and III was $2.95+0.82,8.75+1.20$ and $11.05+1.04$ minutes respectively which was also statistically significant. Intraoperative degree of analgesia in group II and III was comparable to group I. CONCLUSIONS: The use of $0.25 \%$ lignocaine and Atracurium with tramadol or Ketorolac provides comparable analgesia to $0.5 \%$ lignocaine used alone. This decreases the concentration and total dose of lignocaine required but delays the onset of both sensory and motor block.

KEYWORDS: Intravenous regional anesthesia, Lignocaine, Ketorolac, Tramadol, Atracurium, IVRA.

INTRODUCTION: The terms "Regional Anesthesia" was coined in 1902 by Harvey Cushing for his technique of blocking either brachial or sciatic plexus under direct vision during general anesthesia to reduce anesthesia requirements and provide post operative pain relief.

Intravenous regional anesthesia was first described in 1908 by August Gustav Bier, but his technique never gained much popularity ${ }^{1}$. The credit for re-introducing intravenous regional anesthesia goes to Machinnon Holmes in $1963^{2}$. 
Intravenous regional anesthesia is a practical form of anesthesia for short surgical procedures requiring inexpensive equipment, little preparation and minimal technical skills. Being a regional technique it avoids all the complications of general anesthesia, more so in patients coming for emergency surgery as well as patients belonging to ASA class III or IV.

Most important complications in intravenous regional anesthesia are due to the toxicity of the local anaesthetic and will occur if the tourniquet suddenly deflates soon after the local anaesthetic has been injected ${ }^{3}$. Lignocaine in the dose of $1-2 \mathrm{mg} / \mathrm{kg}$ intravenously is safe and effective for treating ventricular arrhythmias ${ }^{4}$ or attenuating the cardiovascular response to endotracheal intubation ${ }^{5}$. To have a good and prolonged analgesia with the same strength of lignocaine, different methods have been proposed like alkalization of local anaesthetics ${ }^{6}$, addition of an opoiod 7 , muscle relaxant or a NSAID 9 .

AIM OF STUDY: To evaluate the efficacy of adding Atracurium with tramadol or ketorolac when lignocaine concentration is reduced to $0.25 \%$ from conventional $0.5 \%$ used for intravenous regional anesthesia.

PATIENTS AND METHODS: After obtaining informed consent and approval from the local ethics committee, this study was conducted in 60 ASA I and II patients with age group 20-60 yrs of either sex, scheduled for elective surgery on forearm and hand.

Patients treated with opioids, patients with acid peptic disorder, coagulation disorder, patients with hypersensitivity to LA and NSAID's were excluded from the study. These sixty patients were randomly divided into 3 equal groups using computer generated random number list so as to receive one of the following solutions in a double blind fashion.

Group I - $40 \mathrm{ml}$ of $0.5 \%$ lignocaine (200 mg)

Group II - 0.25\% lignocaine (100 mg) + $50 \mathrm{mg}$ Tramadol $+2 \mathrm{mg}$ Atracurium diluted in normal saline to make total volume of $40 \mathrm{ml}$

Group III - 0.25\% lignocaine (100 mg) + 30 mg Ketorolac + 2 mg Atracurium diluted in normal saline to make total volume of $40 \mathrm{ml}$

PREANESTHETIC PREPARATION: All the patients were kept nil per oral for about eight hours and were pre-medicated with Tab. Midazolam $7.5 \mathrm{mg}$ at bed time and in the morning of surgery. Baseline records for B.P., R.R., SPO ${ }^{2}$ and Pulse rate were noted.

ANAESTHETIC TECHNIQUE: In the operation theatre one intravenous line was set up in the non-operative limb. In the operative limb, a 22G intravenous cannula was inserted in the most distal vein. Patient was then shifted to operating table and was connected to the non-invasive monitors for getting continuous record of E.C.G, B.P. and $\mathrm{SPO}^{2}$. A double tourniquet was positioned on the upper operative arm with the purpose of eliminating the tourniquet pain and patient comfort. Exsanguination of the limb was done by application of esmarch bandage. In case of painful limb where exsanguinations could not be carried out, limb elevation was given for five minutes. Proximal tourniquet was inflated $100 \mathrm{mmHg}$ above the systolic B.P. of patient. $40 \mathrm{ml}$ of study drug was then given over a period of 1 minute. Once the patient felt uneasiness at proximal tourniquet site or after twenty minutes, whichever was later the distal tourniquet was inflated to the same pressure and the proximal cuff was deflated. The surgery was allowed to proceed once the block was complete. In case of incomplete or partial block, supplemental GA 
was given and the tourniquet was released only after 40 minutes and the patient was excluded from the study.

Onset of sensory block ${ }^{21}$ was assessed by response to pinprick at 1 minute interval

0 - Sharp

1 - Touch only

2 - Cannot feel touch

Score 2 was taken as onset of complete sensory block.

Onset of motor block ${ }^{21}$ - The motor block was assessed according to following scale:

0 - able to move arm against resistance

1 - Inability to move wrist against resistance

2 - Inability to move wrist and elbow against resistance

3 - Inability to move the arm against resistance

Score 3 was taken as onset of complete motor block.

Intraoperative degree of analgesia was evaluated by VAS on $0-10 \mathrm{~cm}$ scale. Complications if any were reported intra and postoperatively.

STATISTICAL ANALYSIS: Statistical analysis was done using ANOVA test. Intergroup comparison was done with Boneferroni's T - test in which the critical value was 2.64.

RESULTS: All the three groups were comparable regarding their demographic data (age, sex and weight). Tendon repair was most commonly performed operation (23) followed by open reduction and nailing (15), implant removal (10) Nerve exploration (7) and contracture release (5).

Figure 1 shows the mean time of onset of sensory block in group I, II and III. There was statistically significant difference between group I \& II, group I \& III and group II \& III in the mean time of onset of sensory block. Figure 2 shows the mean time of onset of motor block in group I, II and III. There was statistically significant difference between group I \& II, group I \& III and group II \& III in the mean time of onset of motor block. Both the onset of sensory and motor block was delayed in group II and III as compared to group I ( $\mathrm{t}-\mathrm{stat}>2.64$ )

Figure 3 shows the VAS score at $10 \mathrm{~min}, 20 \mathrm{~min}, 30 \mathrm{~min}, 40 \mathrm{~min}$, and $50 \mathrm{~min}$ in Group I, II and III. Statistically the difference in VAS score in these three groups using ANOVA test was found to be significant $(\mathrm{P}<0.001)$. Statistically the difference in VAS was found insignificant between group I \& II at 10, 20, 30, 40 and $50 \mathrm{~min}$ (t-stat $<2.64$ ). In group I and III and group II and III the difference in VAS score at 10, 20, 30, 40 and 50 min was found to be statistically significant ( $t$-stat $>2.64$ ).

Two patients in group I experienced dizziness post operatively after release of tourniquet. Two patients in group II had skin rash distal to the tourniquet which faded half an hour after release of tourniquet. Three patients had to be supplemented with general anesthesia and were excluded from the study.

DISCUSSION: Intravenous regional anesthesia technique was first described by August Bier in 1908. He injected Procaine into a superficial vein of a limb previously rendered bloodless by a tourniquet. After a period of wide popularity, it fell into disuse until repopularized by Holmes in 1963 who substituted lignocaine for procaine. Different anaesthetic agents including procaine, 
lignocaine, prilocaine, bupivacaine and mepivacaine have been used for intravenous regional anesthesia. Lignocaine is the local anesthetic most commonly chosen for this technique ${ }^{10}$. Lignocaine $3 \mathrm{mg} / \mathrm{kg}$ administered as $0.5 \%$ solution ensures adequate analgesia and relaxation when used for upper limb surgery. However this much dose of lignocaine has been reported to cause toxic reactions including convulsions, coma, cardiorespiratory depression and even ${ }^{11}$ cardiac arrest.

Toxicity may be due to leakage past the tourniquet after injection caused by either tourniquet failure or build-up of excessively high venous pressure distal to the tourniquet ${ }^{12}$. Lignocaine in a dose of $1-2 \mathrm{mg} / \mathrm{kg}$ has been found to be safe and effective for treating ventricular arrhythmias or attenuating the cardiovascular response to endotracheal intubation. But this much dose has been found to produce insufficient analgesia when used in intravenous regional anesthesia ${ }^{13}$.

To potentiate the effect of low dose lignocaine $(0.25 \%)$ used in intravenous regional anesthesia, various drugs have been added like opioids, muscle relaxants or NSAIDs.

Torda and Klonymus were the first to use muscle relaxants after application of a tourniquet on an extremity to avoid use of high doses of neuromuscular blocking ${ }^{14}$ drugs and deep planes of anesthesia. Elhakim et al reported that both local anesthesia and muscle relaxants exert an effect at the neuromuscular junction ${ }^{15}$. In addition muscle relaxants probably interfere with muscle tone and spasm. The spindle is the sensory end organ of skeletal muscle sending information about fiber length to the brain. Loss of tone and spasm may improve both intraoperative pain and operating conditions.

Opioids have been used in intravenous regional anesthesia either as sole adjunct or in combination with muscle relaxants ${ }^{16}$, peripheral opioid receptor ${ }^{17}$ or by a local anaesthetic action of their own ${ }^{18}$. It has been suggested that previously inactive neuronal opioid receptors may become active in painful inflammatory conditions resulting in reduced neural excitability, inhibited propagation of action potentials an the release of excitatory, pro inflammatory neuropeptides.

Tramadol, a synthetic opioid analgesic produces anti-nociception via an opioid (predominantly $\mu$ ) mechanism and also via a separate non-opioid mechanism (probably related to its ability to inhibit neuronal uptake of nor-epinephrine or serotonin ${ }^{19}$ ).

Vaos et. al was the first to use Ketorolac with intravenous regional anesthesia in the management of patients with sympathetically mediated pain ${ }^{20}$. They reported prolonged pain relief in seven patients who were administered intravenous regional anesthesia with Ketorolac. The idea of using NSAID's during intravenous regional anesthesia originated from the facts that tissue ischemia following tourniquet inflation may lead to the release of inflammatory mediators which could be prevented by anti-inflammatory drugs.

In our study the mean time of onset of sensory and motor block was delayed in group II and III as compared to group I. Our findings are comparable with Palecha ${ }^{21}$ et al (2001) who observed that mean time of onset of sensory and motor block was delayed in group containing $0.25 \%$ lignocaine with pentazocine and pancuronium as compared to the group containing $0.5 \%$ lignocaine.

Statistically the difference in VAS was found insignificant between group I and II at 10, $20,30,40$ and 50 minutes. Our finding is comparable to the observations made by Sztark et al who found that adding on opioid and muscle relaxant to $0.25 \%$ lignocaine reduced the dose of lignocaine to non-toxic level for the same quality of analgesia as provided by the use of $0.5 \%$ lignocaine in intravenous regional anesthesia. 
Statistically the difference in VAS score was significant between group I and III and group II and III (t-stat $>2.64$ ). This is in contrary to the finding of Reuben ${ }^{22}$ et al who found that addition of $60 \mathrm{mg}$ of Ketorolac of $0.5 \%$ lignocaine for intravenous regional anesthesia provided better intra-operative analgesia. Reason for getting a better outcome in intravenous regional anesthesia in this study could be use of high concentration $(0.5 \%)$ of local anaesthetic combined with high dose of Ketorolac (60mg) as compared to low conc. of lignocaine $(0.25 \%)$ and low dosage of Ketorolac (30mg) used in our study.

Thus the addition of tramadol and Atracurium to $0.25 \%$ lignocaine provides the same quality of intraoperative analgesia as compared to $0.5 \%$ lignocaine but the combination had delayed onset of sensory and motor block. Addition of Ketorolac $30 \mathrm{mg}$ and $2 \mathrm{mg}$ Atracurium to $0.25 \%$ lignocaine does not provide the same quality of analgesia as compared to $0.5 \%$ lignocaine although it provides clinically acceptable surgical anaesthesia. So the use of $0.25 \%$ lignocaine with these adjuncts allows a reduction in total dose of lignocaine while achieving the same degree of intraoperative analgesia in intravenous regional anesthesia.

\section{REFERENCES:}

1. Beir: A new method for local anesthesia in the extremities. Ann- Surg 1908; 48:780

2. Holmes C M C K: Intravenous regional anesthesia - A useful method of producing analgesia of limb. Lancet 1963 I: 245.

3. Casey W F: Intravenous regional anesthesia (Bier's Block) update in Anesthesia Issue I (1992) Article 2.

4. Gianely R, Vonder G J, Spivack A P, Harrison D C.: Effect of Lignocaine on ventricular arrhythmia's in patients with coronary heart disease N Eng J. Med. 1967; 277: 1215 - 9.

5. Afsar S N, Abdulla W: The effect of various administration routes of lignocaine on hemodynamics and ECG rhythm during endotracheal intubation. Acta Anaesthesia l Belg 1990; 41: 17-24.

6. Benolabed M, Jullian P, Guelmi K, Hamza J, Bonhamn L, Bendamou D: Alkalinization of lignocaine for intravenous regional anesthesia. Regional Anaesthesia 1990; 15; 59-60.

7. Abdulla Wailed Y, Fadhil Nihal M: A new approach to intravenous regional anesthesia. Anesthesia Analgesia 1992; 75:597-601.

8. Sztark F, Thicoipe M, Garrigus F J F, Lassie P, Petijean M.E, Dabadie P: The use of $0.25 \%$ lignocaine with fentanyl and pancuronium for intravenous regional anesthesia. Anathesia Analgesia 197; 84: 777-779.

9. Reuben Scoltis, Steinberg Robert B, Krctzer Joel M, Duprat Karen M: Intravenous regional anesthesia using lignocaine and ketorolac. Anaesthesia Analgesia 1995; 81: 110-3.

10. Simon M A M, Gielen M J M, Vrec T B, Booji L H D J: Disposition of lignocaine for intravenous regional anesthesia during day case surgery. European Journal of Anaesthesia 1998; 15:32-37.

11. Heath M L:. Death after intravenous regional anesthesia. Br. Med. J 1982: 285:913-4.

12. Grice S C, Morell R C, Balestrieri F J, Stamp D A, Howard C: Intravenous regional anesthesia evaluation and prevention of leakage under the tourniquet. Anaesthesiology 1985; 63: A221.

13. Urban B J, Mckain C W: Onset and progression of intravenous regional anesthesia with dilute lignocaine. Anaesthesia Analgesia 1982; 61:834-8.

14. Torda T A G, Klonymus D H: The regional use of muscle relaxants. Arch. Surg. Vol. 95, Feb 1907.

15. Elhakim M, Sadek R A: Addition of atracurium to lignocaine for intravenous regional anesthesia. Acta Anaesthesial Scand 1994 ; 38: 542-544. 
16. Abdulla Wailed Y, Fadhil Nihal M: A new approach to intravenous regional anesthesia. Anesthesia Analgesia 1992; 75: 597-601.

17. Stein Chritoph, D O Z Priv: Peripheral mechanism of opioid analgesia. Anaesthesia Analgesia 1993; 76: 182-19.

18. Power I, Brown D J, Wildsmith J A W: The effect of fentanyl, meperidine and diamorphine on nerve conduction in vitro. Regional Anaesthesia 1991; 16: 204-8.

19. Raffa B. Robert. Opioid and Nonopioid components independently contributes to the mechanism of action of tramadol, an atypical opioid analgesic. The Journal of Pharmacology and experimental therapeutics 1992 Vol. 260 No. 1.

20. Vanos D N, Ramanmurthy S Hoffman J Intravenous regional block using ketorolac: preliminary results in the treatment of reflex sympathetic dystrophy Anaesthesia Analgesia 1992; 74: 139-141.

21. Palecha S, Gupta H.K, Tind S S, Sharma S: The use of $0.5 \%$ and $0.25 \%$ lignocaine with pentazocine and pancuronium for intravenous regional anesthesia - A comparative study Indian Journal of Anaesthesia 2001: 45(2): 133-135.

22. Reuben Scolts, Steinberg Robert B, Krectzer Joel M, Duprat Karen M: Intravenous regional anesthesia using lignocaine and ketorolac. Anaesthesia Analgesia 1995; 81: $110-$

Table 1 - Comparison of demographic profile of patients

\begin{tabular}{|c|c|c|c|c|}
\hline \multicolumn{2}{|c|}{ Age Mean (yrs) } & \multirow[t]{2}{*}{ Sex } & \multicolumn{2}{|c|}{ Weight (kg) } \\
\hline Male & & & Female & \\
\hline Group 1 & $\begin{array}{l}33.35+ \\
4.69\end{array}$ & 4 & 16 & $\begin{array}{l}55.7+ \\
3.65\end{array}$ \\
\hline Group 2 & $\begin{array}{l}31.95+ \\
6.71\end{array}$ & 4 & 16 & $\begin{array}{l}56.7+ \\
3.32\end{array}$ \\
\hline Group 3 & $\begin{array}{l}33.05+ \\
6.09\end{array}$ & 5 & 15 & $\begin{array}{l}56.75+ \\
3.24\end{array}$ \\
\hline
\end{tabular}

Table 2 - Comparison of surgical procedures and duration of surgery

\begin{tabular}{|l|l|l|l|}
\hline $\begin{array}{l}\text { Surgical } \\
\text { Procedures }\end{array}$ & Group I & Group II & Group III \\
\hline Tendon repair & 8 & 7 & 8 \\
\hline $\begin{array}{l}\text { Open reduction } \\
\text { and nailing } \\
\text { (Hand and } \\
\text { finger) }\end{array}$ & 5 & 6 & 4 \\
\hline $\begin{array}{l}\text { Implant } \\
\text { removal }\end{array}$ & 3 & 4 & 3 \\
\hline $\begin{array}{l}\text { Contracture } \\
\text { release }\end{array}$ & 1 & 2 & 2 \\
\hline $\begin{array}{l}\text { Nerve } \\
\text { exploration }\end{array}$ & 3 & 1 & 3 \\
\hline $\begin{array}{l}\text { Duration of } \\
\text { surgery in } \\
\text { minutes. }\end{array}$ & $46.3+7.29$ & $44.3+4.41$ & $43.65+4.34$ \\
\hline
\end{tabular}




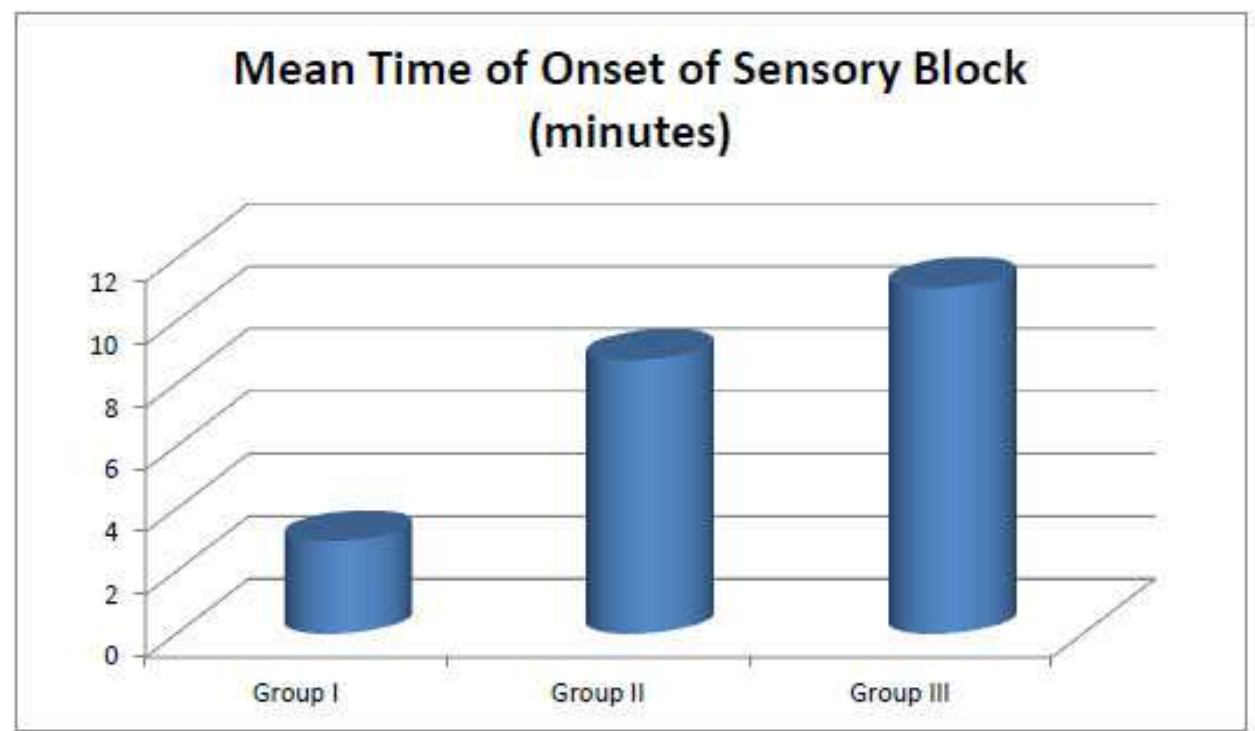

Figure 1

Inter Group Comparison \& Statistical Significance of the Mean Time of Onset of Sensory Block

\begin{tabular}{ccc}
\hline Group & 't' statistics & Inference \\
\hline I-II & 17.68 & $\mathrm{~S}$ \\
II-III & 07.01 & $\mathrm{~S}$ \\
I-III & 24.69 & $\mathrm{~S}$ \\
\hline Critical Value $=2.64$ & $>2.64$ - Significant $(\mathrm{S})$ & $<2.64$ - Non Significant $(\mathrm{NS})$
\end{tabular}




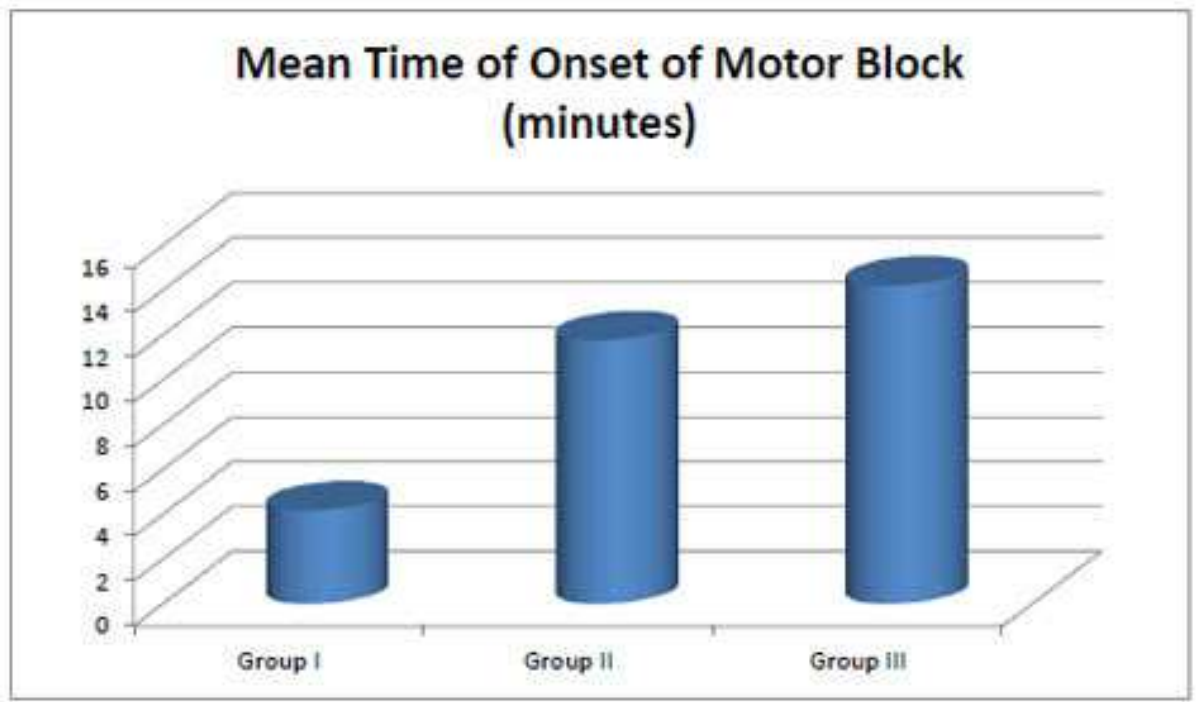

Figure 2

Inter Group Comparison \& Statistical Significance of the Mean Time of Onset of Motor

Block

\begin{tabular}{ccc}
\hline Group & 't' statistics & Inference \\
\hline I-II & 30.07 & $\mathrm{~S}$ \\
II-III & 09.96 & $\mathrm{~S}$ \\
I-III & 24.69 & $\mathrm{~S}$ \\
\hline Critical Value $=2.64$ & $>2.64$ - Significant (S) & $<2.64$ - Non Significant (NS)
\end{tabular}

Figure 3 - Intraoperative analgesia by visual analogue scale $(0-10 \mathrm{~cm})$

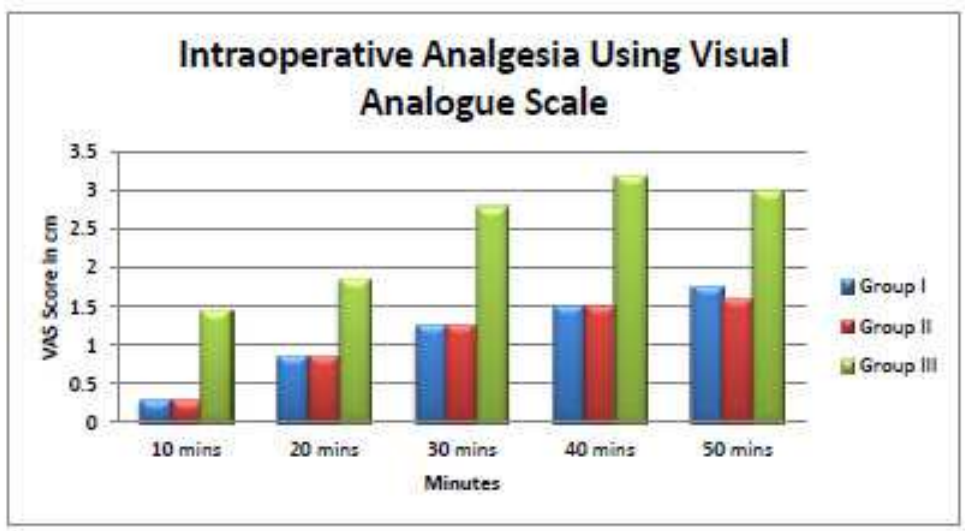

